\title{
¿EXISTE DISCRECIONALIDAD EN LA DECISIÓN JUDICIAL?
}

\begin{abstract}
Juan Antonio García Amado*
Resumen

Dos tipos de doctrinas jurídicas han tratado de negar la discrecionalidad judicial: por un lado, el formalismo ingenuo del siglo XIX, propio de la Escuela de la Exégesis, en Francia, y de la Jurisprudencia de Conceptos, en Alemania; por otro lado, el formalismo sofisticado de fines del siglo XX, que primero integra derecho y moral social y, después, moraliza la Constitución positiva para que en el derecho positivo se contenga una única solución correcta para cada caso posible. Por contra, el positivismo jurídico del siglo XX ha visto en la discrecionalidad judicial una consecuencia, tan inevitable como conveniente, de los caracteres de todo sistema jurídico real.
\end{abstract}

Palabras clave: Discrecionalidad - decisión judicial - juicio valorativo.

\begin{abstract}
Two different sets of legal theories have denied that judges have any discretion when deciding cases. The first was the naive formalism as practiced in the 19th century in France for the Exegesis school and the Conceptual Jurisprudence School (Begriffsjurisprudenz) in Germany. On he other hand, was the sophisticated formalism of the late 20th century that integrated the right with the social ethics, both establishes a connection between law and social morality, and undertakes a moral reading of the constitution so that positive law could offer one right answer for every case. Against all of this, the juridic positivism of the 20 th century has regarded judicial discretion as a consequence, so unavoidable as unadvisable of the structure of any existing legal system.
\end{abstract}

Key words: Discretionality - judicial decision - valuing judgment.

\section{Sumario}

1. Introducción. 2. Doctrinas negadoras de la existencia de discrecionalidad judicial. 3. Doctrinas que afirman la discrecionalidad judicial.

* Licenciado y Doctor en Derecho por la Universidad de Oviedo - España. Profesor de Filosofía del Derecho en la Universidad de León - España. 


\section{INTRODUCCIÓN}

¿Qué significa aquí discrecionalidad? Con este término aludimos a la libertad de que el juez disfruta a la hora de dar contenido a su decisión de casos sin vulnerar el Derecho. Por tanto, cuando afirmamos que tal discrecionalidad existe en algún grado, queremos decir que el propio Derecho le deja al juez márgenes para que éste elija entre distintas soluciones o entre diferentes alcances de una solución del caso. Así pues, si hay discrecionalidad significa que al juez las soluciones de los asuntos que decide no le vienen dadas y predeterminadas enteramente, al cien por cien, por el sistema jurídico, sino que éste, en medida mayor o menor, le deja espacios para escoja entre alternativas diversas, pero compatibles todas ellas con el sistema jurídico.

Tal cesión de espacios decisorios al juez, semejante campo para su decisión discrecional, puede deberse a dos causas: o bien a que las mismas normas hayan querido expresamente remitir al juez la fijación de la pauta decisoria, caso por caso, como cuando son esas mismas normas las que dicen que en un determinado asunto el juez fallará discrecionalmente, decidirá en equidad, etcétera; o bien a que las normas jurídicas, prácticamente todas, están hechas de un material lingüístico que es por definición poroso, abierto, indeterminado en alguna medida, por lo que siempre pueden aparecer casos cuya solución resulte dudosa o equívoca a la luz de dichas normas, debiendo el juez concretarlas y completarlas por vía de interpretación o integración. En lo que sigue atenderemos principalmente a esta última causa posible de discrecionalidad judicial.

Durante mucho tiempo, como veremos, se admitía con dificultad que el juez pudiera disponer de campo para sus discrecionales opciones, aun dentro de los márgenes que la ley deje abiertos por razón de su materia prima, el lenguaje. Y hoy algunas influyentes teorías del Derecho vuelven al rechazo de la discrecionalidad. Pero, entretanto, ha ido quedando claro que la libertad que los jueces pueden usar en su labor tiene dos manifestaciones, una positiva y admisible, la otra negativa y rechazable. La primera recibe el nombre de discrecionalidad y, repetimos, alude a aquella medida de libertad decisoria del juez que resulta inevitable e ineliminable de su cometido, por causa de los caracteres mismos que posee la materia prima de las normas, el lenguaje ordinario. La segunda, que se debe combatir, se denomina arbitrariedad. Una decisión judicial es arbitraria cuando el juez decide libremente, sí, pero concurriendo todas o alguna(s) de las siguientes notas:

a) Vulnera las pautas decisorias que el sistema jurídico le fija para el caso, en lo que dichas pautas tengan de claras y terminantes. 
Conviene aquí hacer una muy elemental aclaración. Que ninguna norma general y abstracta sea capaz de determinar al cien por cien la solución de todos los casos que prima facie se le puedan someter, que respecto de cualquier norma pueda haber casos dudosos cuya solución no es clara y para los que quepan, con igual respeto de las normas, soluciones diversas entre las que el juez tenga que optar, no significa que a veces no haya casos claros y soluciones precisas. Son los llamados casos fáciles. Pongamos un ejemplo bien simple. Si una norma tipifica como delito el robo que se realice valiéndose de armas, cabría discutir si un palo o un puñal de juguete con apariencia real son o no son armas a tales efectos, con lo que respecto de esos casos puede pensarse que el juez puede elegir entre el sí y el no, en función de cómo interprete el término "arma" que en la norma figura; ahora bien, nadie en su sano juicio dudaría de que si el ladrón se vale de un fusil perfectamente real, cargado y montado para disparar, el robo acontece mediante el uso de un arma, pues no cabe razonablemente, en modo alguno, negarle a dicho fusil tal condición. Así que el juez que dijera que ese fusil no es un arma estaría incurriendo en arbitrariedad, pues nada hay más arbitrario que la negación de la perfecta evidencia.

b) Se demuestra que lo que guía la elección del juez son móviles incompatibles con el sistema jurídico que aplica y con su función dentro de él, como interés personal, afán de medro, propósito de notoriedad, precio, miedo, prejuicios sociales o ideológicos, etcétera.

c) Cuando el juez no da razón ninguna de su fallo o cuando su motivación del mismo contienen razones puramente inadmisibles, ya sea por absurdas, antijurídicas o incompatibles con los requerimientos funcionales del sistema jurídico. Un juez que, por ejemplo, fundamentara expresamente su fallo en cosas tales como una revelación divina, los contenidos de una determinada religión, los postulados de un determinado partido político, sus gustos particulares o su personal sentido de la justicia estaría incurriendo en arbitrariedad en este sentido, tanto o más que el que se abstiene de motivar su fallo.

Después de estas mínimas precisiones conceptuales, puede quedarnos claro que la discrecionalidad judicial no necesariamente es mala (aunque hay doctrinas, como vamos a ver, que tratan de evitarla por completo) y muchos creemos, en todo caso, que es inevitable. Por contra, la arbitrariedad ha de perseguirse siempre, es el antivalor judicial por excelencia.

Sentado esto, podemos ya realizar un pequeño repaso histórico y comprobar qué doctrinas han negado y niegan la discrecionalidad judicial y cuáles la han presentado como inevitable o, incluso, positiva. 


\section{DOCTRINAS NEGADORAS DE LA EXISTENCIA DE DISCRECIONA- LIDAD JUDICIAL}

Las doctrinas que combaten la discrecionalidad judicial lo hacen por dos razones entrelazadas: por un lado, por la convicción de que la discrecionalidad judicial no es conveniente; por otro lado, por la creencia de que la discrecionalidad judicial es evitable, y lo es porque el sistema jurídico posee caracteres o propiedades que lo ponen en condiciones de proporcionarle el juez la solución única y precisa de cada caso, sin que las valoraciones o elecciones de éste sean, por tanto, necesarias para colmar las indeterminaciones o equivocidades de dicho sistema, pues no habría tales.

\subsection{El formalismo ingenuo del siglo XIX: Escuela de la Exégesis y Jurispru- dencia de Conceptos}

Esa negación de la discrecionalidad judicial aconteció en la doctrina dominante durante prácticamente todo el siglo XIX, de la mano principalmente de la Escuela de la Exégesis, en Francia, y de la Jurisprudencia de Conceptos, en Alemania.

Estas dos escuelas tenían en común su carácter ingenuamente formalista en materia de decisión judicial. Sostenían ambas que la decisión del juez tenía un carácter puramente formal, ya que consistía en un simple silogismo a partir de premisas que al juez le venían perfectamente dadas y acabadas. La premisa mayor o normativa se la proporcionaba al juez con plena claridad y coherencia el sistema jurídico, de modo que el juez no tenía ni que inventarla ni que completarla ni que interpretarla. Subyacía a semejante confianza la convicción de que el sistema jurídico posee tres caracteres que hacen su perfección en tanto que fuente plena de las decisiones judiciales: a) el sistema jurídico es completo, de manera que no hay lagunas y, por tanto, nunca va a tener el juez que "inventar" para un caso la solución que ninguna norma preestablecida contempla; b) el sistema jurídico es coherente, $y$, por tanto, no hay en él antinomias, con lo que nunca va a suceder que un juez se tope con que para el caso que le toca resolver se contienen en el ordenamiento vigente normas que prescriben soluciones contradictorias entre sí y; c) el sistema jurídico es claro, de manera que las soluciones que para cada caso prescribe están dadas con nitidez suficiente como para hacer su interpretación o bien innecesaria o bien muy sencilla. En resumen, para cada caso que el juez tenga que fallar el sistema jurídico proporciona siempre una solución, sólo una y perfectamente clara y precisa. 
En cuanto a la premisa menor del silogismo judicial, estaría constituida por los hechos del caso, y también éstos se le ofrecen al juez con total independencia de cualquier juicio suyo. Los hechos están ahí y su prueba es un proceso objetivo en el que no queda margen para la evaluación personal del juzgador; las cosas son o no son, y son o no con independencia de las opiniones del juez. El juez, por tanto, juzga de los hechos que son, no de los que a él le parecen o de cómo a él le parecen.

Otra forma de explicar lo anterior es mediante la teoría de la subsunción, en su versión decimonónica. Las mencionadas escuelas sostenían que la aplicación del Derecho, la solución de los casos por el juez, es mera subsunción de los hechos bajo la norma que los abarca y los resuelve, y esa subsunción es una labor poco menos que puramente mecánica.

Con una imagen gráfica podemos ilustrar bien qué representaba esa idea de la decisión judicial como mera subsunción. Supongamos que cada norma jurídica es como un molde, y que cada uno de esos moldes tiene una forma distinta y perfectamente perfilada. Cuando un juez tropieza con el asunto que tiene que decidir, toma ese asunto, cual si fuera un objeto material con una forma determinada y peculiar, y se pone a buscar para él, para ese objeto, el molde que exactamente se le acomoda. Partimos de que para cada caso (objeto) habría siempre un molde en el sistema jurídico (pues el sistema, como hemos dicho, es completo, no tiene lagunas), sólo uno, nunca encajará bajo dos moldes distintos (pues el sistema no posee antinomias) y el encaje bajo ese molde que a cada caso corresponde será siempre exacto, sin vanos ni márgenes, pues el sistema es claro. Así que el juez acabará siempre encontrando el molde normativo en que el objeto de su decisión, el caso, encajará perfectamente. Y su fallo derivará con la evidencia y el automatismo de la siguiente imagen, que completa el cuadro: una vez hallado el molde en que el caso encaja, el juez lo toma y ve en él, en el molde, la solución prevista. Es como si lo levantara y por debajo leyera: "para el caso C (el que acaba de "subsumir" o encajar en ese molde) la solución es $S$ ", y eso que dentro o debajo del molde está escrito es lo que el juez traslada a su fallo del caso. Sin más y, sobre todo, sin que nada tenga que añadir o poner de su parte, pues el juez no es sino el operario que mete el caso en su molde y copia la solución que en éste encuentra, sin cambiarla, sin complementarla con nada, sin que acontezca ninguna valoración de su cosecha y, con ello, sin que tenga margen ninguno para que sus preferencias personales o sus convicciones determinen en nada el contenido del fallo. Ahí no queda el más mínimo resquicio para la discrecionalidad judicial, pues, en síntesis, cada caso tiene prediseñada en el sistema jurídico una y sólo una solución correcta (un molde perfecto), y esa 
única solución correcta el juez se limita a averiguarla, a descubrirla, pues está ahí, en el sistema, antecediendo a todo juicio o acción del juez, esperando ser hallada y aplicada. El juez no manipula ni recrea el molde ni el caso, sólo introduce el segundo en el primero y lee la solución.

Escuela de la Exégesis y Jurisprudencia de Conceptos comparten lo que acabamos de decir, pero mantienen también diferencias que se explican por el contexto histórico de cada una. La Escuela de la Exégesis se desarrolla en Francia a partir de la entrada en vigor, en 1804, del Código de Napoleón, el Código Civil Francés. Téngase en cuenta que en esos tiempos iniciales del movimiento codificador en Europa regía la fortísima convicción de que los códigos civiles eran una obra perfecta de la razón jurídica, razón cristalizada en el llamado mito del legislador racional. El legislador, encarnación de la nación de una manera o de otra, por definición no yerra ni en los contenidos ni en la forma de las normas que produce. Cuando esas normas se aglutinan y sistematizan en un Código, éste es expresión suprema de la razón social y jurídica y fuente autosuficiente de toda juridicidad y toda decisión. Así que el juez tendrá que decidir cada caso subsumiendo sus perfiles bajo el molde de la correspondiente norma del Código. Añádase a esto que la doctrina francesa de tal época desconfiaba grandemente de los jueces, tenidos por reaccionarios y cómplices o nostálgicos del antiguo régimen estamental. Por eso en algunas de las primeras codificaciones (aunque no en la francesa, en la que no pasó de algún anteproyecto) se llegaron a contener prohibiciones expresas de que el juez interpretara las normas contenidas en el respectivo Código ¿Para qué interpretar si todo está claro y es perfecto? La interpretación de la ley era vista con desconfianza suma, como vía fácilmente aprovechable por el juez para introducir sus propias valoraciones en perjuicio de las del legislador y con daño para la norma. Toda discrecionalidad judicial, en consecuencia, era rechazada como equivalente a pura y simple arbitrariedad. Con el Código basta y sobra, en él están, y están perfectos, todos los moldes necesarios para subsumir los casos, ni hace falta cambiar ninguno ni repararlo ni añadir otros.

En Alemania las cosas eran distintas. Es bien sabido que en los territorios alemanes durante todo el siglo XIX el sistema de fuentes del Derecho era un totum revolutum, sin orden claro ni jerarquía precisa, integrado por elementos del Derecho romano de Pandectas, pasado por el tamiz de la doctrina romanista, de derecho histórico germánico, de derecho consuetudinario, etcétera. $Y$, si el derecho positivo era tan caótico, contradictorio y lagunoso, ¿bajo qué subsumían?, ¿dónde encontraban los moldes? En los conceptos, y de ahí el nombre de esta escuela. 
Se consideraba que el sistema jurídico estaba, en su fondo o esencia, integrado no por normas positivas, legisladas (éstas eran sólo la parte superficial del sistema, inexacta o meramente aproximativa), sino por ciertas esencias o categorías cuya naturaleza no es ni empírica ni psíquica ni social, sino ideal. Los componentes reales y supremos del sistema jurídico, bajo los que el juez puede y debe subsumir cada caso que le llegue, son esas ideas objetivas, esos conceptos, esas esencias o categorías que prefiguran y encierran en sí la regulación detallada de cada institución de las que componen el Derecho. Veámoslo con un ejemplo. Si el juez tiene que resolver algún asunto de Derecho matrimonial, haya ley positiva al respecto o no la haya, sea clara u oscura, no importa gran cosa, pues adonde tiene ese juez que acudir para buscar las soluciones es a la idea de matrimonio, idea que subsiste al margen de los lugares y de la historia y en la que se encierra todo lo que el juez necesita saber para resolver sobre si el matrimonio es válido, sobre cualquiera de sus efectos, etcétera. Y lo mismo que ejemplificamos con el matrimonio vale para cualquier otra institución, ya sea, por seguir con más ejemplos, la propiedad, el testamento, un contrato, etcétera. El sistema jurídico forma una pirámide de conceptos o esencias jurídicas, en cuya cúspide está el concepto más general y abarcador, el de autonomía de la voluntad, y en los sucesivos peldaños descendentes conceptos menos generales, cada uno de los cuales es desarrollo o plasmación, para un ámbito más concreto, del concepto superior y, al tiempo, "padre" o condicionante de los conceptos inmediatamente inferiores.

Con una cierta simplificación o caricatura podemos representar esa escala así: la autonomía de la voluntad, en la cúspide, se desarrolla en o engendra el negocio jurídico, que, a su vez, se desarrolla en o engendra el contrato (y el testamento, hermano del contrato), el cual, a su vez, se desarrolla en o engendra en los diversos contratos (compraventa, arrendamiento, depósito, etcétera). Así que el juez sólo tienen que ver bajo cuál de tales categorías o esencias se subsume el caso que tiene entre manos y le bastará con aplicarle las prescripciones que en esa familia de moldes, del más amplio al más exactamente ceñido a su perfil, se contienen para él: si encaja bajo la compraventa, le aplicará lo específico de la compraventa, como idea, unido a lo general de todos los contratos, unido, en un peldaño más alto, a lo común para todos los negocios jurídicos y regido todo por el principio supremo, padre primigenio de todo el Derecho privado, de autonomía de la voluntad.

Ese sistema jurídico formado por esencias de lo jurídico es perfecto. El derecho positivo puede tener defectos. El verdadero Derecho, que es ese derecho integrado por formas ideales, es perfecto. Bajo su amparo, está de más toda discrecionalidad judicial. 
Resumamos esta ideología dominante en el pensamiento jurídico del XIX:

a) El sistema jurídico es perfecto, en cuanto que contiene en sí (ya sea bajo la forma de artículos de un Código -Francia- ya de esencias prepositivas, ideales -Alemania-) siempre una única solución correcta para cada caso que el juez haya de decidir.

b) La actividad decisoria del juez se explica como pura subsunción del caso bajo la correspondiente regla del sistema, por lo que su actividad reiviste un carácter cuasimecánico.

c) El razonamiento en que esa actividad desemboca tiene la estructura de un siligismo simple, del que la premisa mayor es dicha regla y la premisa menor los hechos, sin que estén presentes en él ulteriores premisas o presupuestos de ningún tipo, por lo que sólo de esas dos premisas y de ninguna más se deriva, con necesidad lógica, el fallo a modo de conclusión.

d) La esencia de la labor judicial es cognoscitiva. Esto significa que en realidad el juez no es propiamente alguien que decide, sino que meramente conoce lo que para un caso dispone como solución necesaria el sistema jurídico, limitándose a extraer las consecuencias del sistema para ese caso, pero sin que tal labor tenga ribetes ni morales, ni políticos ni de ningún otro tipo que suponga elección valorativa.

e) En consecuencia, el método correcto que ha de guiar la decisión judicial no es un método decisorio, sino un método de conocimiento. El juez se parece mucho más al científico que al legislador, y está mucho más cerca del dogmático (civilista, penalista, etcétera) que estudia en sede teórica el Derecho y descubre sus "profundidades", que del político que legisla y elige entre opciones regulativas.

Este formalismo ingenuo de la Escuela de la Exégesis y de la Jurisprudencia de Conceptos comenzó su crisis en las últimas décadas del siglo XIX y ya no pudo superar las críticas devastadoras de autores como el Jhering de la segunda época o de Gény, primeramente, y luego los embates definitivos de la Escuela de Derecho Libre o de las distintas corrientes del Realismo Jurídico o de Kelsen. Más adelante volveremos a algunas de esas corrientes, al hablar de las doctrinas que afirman la discrecionalidad judicial. Pero baste aquí indicar que lo que entre todos fueron dejando sentado con rotundidad es que ningún sistema jurídico posee aquellos tres idílicos caracteres de plenitud (ausencia de lagunas), coherencia (ausencia de antinomias) y claridad (ausencia de in- 
determinación). Y si resulta que hay lagunas, antinomias y, sobre todo, indeterminación constitutiva del lenguaje del Derecho, ¿cómo negar que ciertos márgenes, al menos, de discrecionalidad judicial son ineludibles? ¿Quién sino el juez puede, por tanto, precisar, por vía de interpretación, cuál de los varios significados que los términos de una norma pueden admitir ha de regir para el caso?

Pero también en el pensamiento jurídico parece que rige la ley del péndulo, y el formalismo decimonónico, en lo que tenía de afirmador de la perfección del sistema jurídico y de negador de la discrecionalidad judicial, ha regresado con plena pujanza a fines del siglo $X X$ y domina hoy, en pleno siglo XXI, esta vez de la mano de doctrinas que podemos denominar axiologismo jurídico y que están bien representadas por autores como Dworkin y por los teóricos más radicales de esa doctrina que se viene denominando neoconstitucionalismo y que podría ejemplificarse en autores como el Zagrebelsky de El Derecho dúctil.

\subsection{El formalismo nada ingenuo de fines del siglo $X X$ : de algunos alemanes dudosos a Dworkin, y de Dworkin al neoconstitucional ismo.}

Hay tres doctrinas que, grosso modo, coinciden en las siguientes ideas: el sistema jurídico se compone de estratos, y en tales estratos hay que distinguir ante todo un estrato superficial y otro profundo o subterráneo. En el primero se hallarían las normas de derecho positivo, en su formulación más convencional, es decir, los enunciados jurídicos que el legislador produce y que se agrupan en códigos, leyes, reglamentos... Pero por debajo de ese nivel, sosteniéndolo y dándole su inspiración, su sentido último, su razón de ser y la perfección que le falta se encuentra el estrato profundo, cuya materia ya no es lingüística sino axiológica, no empírica sino ideal, y no imperfecta, esto es, lagunosa, incoherente y oscura, sino perfecta, pues contiene solución única, consistente y definida para cualquier caso.

Para estas doctrinas el sistema jurídico sería algo similar a un iceberg. Un iceberg tiene una parte que sobresale por encima de la superficie del mar y que cualquiera puede ver sin necesidad de sumergirse. Pero su parte más consistente se encuentra por debajo de esa línea de superficie y sólo es visible para quien conozca a fondo lo que es un iceberg o domine la técnica de buceo. Un sistema jurídico sería igual. Hay una parte superficial, en forma de los enunciados jurídicos que cualquiera puede leer e interpretar; pero, por debajo, está la parte sumergida, que sostiene la otra y que es mucho más grande y contundente. Conocer el Derecho no es sólo ver y entender lo que a la vista de 
todos está, la superficie del iceberg, sino saber calar en lo profundo y hallar lo que ahí se encuentra, valores; supone ver más allá de la superficie, ser capaz de contemplar lo que no está a la vista de todos.

Vemos, en resumidas cuentas, que estas doctrinas axiologistas desdoblan la naturaleza del Derecho y, al tiempo y complementariamente, desdoblan en dos la epistemología jurídica, el tipo de conocimiento que se requiere para saber del Derecho. Hay siempre una naturaleza superficial y una naturaleza profunda del Derecho, constituida la primera por enunciados jurídicopositivos y la segunda por valores. $Y$, al tiempo, hay un conocimiento superficial del Derecho, propio de quienes sólo ven en él enunciados que pueden ser comprendidos en sus términos e interpretados, con márgenes de elección discrecional, en sus indeterminaciones; $\mathrm{y}$ un conocimiento profundo del Derecho, al alcance sólo de quien domine el método de "excavación" o "buceo" que permite superar el dato superficial, equívoco, dudoso y, a veces, hasta falso o engañoso, y captar las verdades plenas e indubitadas que en el fondo del sistema se guardan, al modo de solución correcta para cada caso que al Derecho se someta. Ese método se solía describir como capacidad que nuestra razón posee para escuchar los dictados grabados en nuestra naturaleza, o en el orden inmanente a la Creación. Pero en las últimas épocas más bien se explica unas veces como empática capacidad del juez sabio y virtuoso para descubrir la coherencia que en el fondo mantienen los valores vigentes en una sociedad, por mucho que en al superficie parezca que no hay tal armonía valorativa, sino una tensión dialéctica, fruto del pluralismo constitutivo de las sociedades modernas y democráticas; o como vía que recorre, para llegar a la verdad, aquella parte de nuestra razón que se ocupa de los asuntos valorativos (política, moral, Derecho...) y que se llama razón práctica.

Como es obvio, el ancestro teórico de estas doctrinas es el iusnaturalismo tradicional, en cualquiera de sus manifestaciones, tanto el de base teológica como el racionalista. Pero no podemos ignorar que en el último siglo el iusnaturalismo ha sido una doctrina que ha dicho muy poco en materia de decisión judicial y ha vivido replegado y limitándose a debatir las condiciones de validez de la norma positiva. En materia de interpretación y aplicación del Derecho la función que tradicionalmente el iusnaturalismo cumplía la han asumido doctrinas como éstas que ahora vamos a examinar: Jurisprudencia de Valores, Dworkin y neoconstitucionalismo. No digo con esto que merezcan con propiedad el nombre de iusnaturalismos, sino que son en nuestro tema equivalentes funcionales del iusnaturalismo, aunque los mimbres con los que se elaboran sean diferentes en algún grado. 
Vamos ahora a pasar sucintamente revista a las tres variantes que nos interesan, atendiendo con preferencia al tema que nos ocupa, la negación de la discrecionalidad judicial.

El mejor antecedente del actual neoconstitucionalismo se encuentra en la doctrina alemana llamada Jurisprudencia de Valores (W ertungsjurisprudenz). Para comprender el cómo y el porqué del giro que esta escuela imprime a la teoría y la praxis jurisprudencial alemana de los años cincuenta y sesenta debemos comenzar por echar un vistazo al contexto histórico del que nace.

De 1919 a 1933, bajo la Constitución de Weimar, el grueso de los profesores de Derecho y de los jueces alemanes comulgaba con un pensamiento fuertemente estatista, que veía en el Estado suprema encarnación de la nación, plasmación del espíritu del pueblo alemán y ser con derechos propios que se anteponían a los derechos del individuo. El Estado era sustancia colectiva con vida propia, expresión de una unión cuasimística entre los ciudadanos portadores de los atributos nacionales, persona colectiva cuyo interés propio trasciende los intereses individuales de los ciudadanos y les da su sentido aglutinador. Era, pues, este pensamiento jurídico-político entonces dominante un pensamiento marcadamente hostil frente a la filosofía política liberal, frente a la Constitución entendida como sancionadora de la soberanía popular, como portadora de normas a las que la acción del Estado habría de someterse y como proclamadora y protectora de derechos y libertades individuales que ponen límite a la acción posible del Estado frente a sus ciudadanos. La noción misma de ciudadano calaba mal en esta filosofía, que más bien quería para el Estado súbditos y que veía en los derechos que el súbdito pudiera tener una concesión del Estado y no el reconocimiento de su dignidad y su valor frente a él o antes de él. El modelo imperante en Alemania no era el del Estado de Derecho, sino el del Derecho del Estado. Y el tipo de positivismo que regía no era aquel positivismo jurídico kelseniano que mantiene que el Estado no es más que una forma de ver un sistema jurídico vigente, negándole así al ser estatal toda entidad propia y cuestionando de raíz la metafísica estatista. El positivismo mayoritario era de un jaez completamente diferente, era positivismo estatista, cuyo postulado central podríamos resumir así: todo lo que en el Derecho y la vida social cuenta (las normas jurídicas, los derechos individuales, las instituciones...) nace del Estado y se debe al Estado, nada hay fuera del Estado, nada se debe tolerar si perjudica la vida propia y la supervivencia del Estado. Y el vínculo entre el Estado y la sociedad es un vínculo natural, metafísico, no un vínculo formal o meramente jurídico-político. Frente a la mecánica democrática y representativa, propia del liberalismo y tenida por disolvente y decadente, se afirmaba la naturalidad de una relación orgánica, viva, entre 
la sociedad y su gobierno. El Emperador, antes, o el Presidente de la nación, luego, no son cabeza del Estado en sentido metafórico, sino en sentido propio, pues Estado y sociedad no son sino un mismo ser vivo, del que la sociedad es cuerpo y su supremo jefe es cabeza. Tales imágenes las había ido forjando con continuidad y esmero la iuspublicística alemana a lo largo de todo el siglo XIX, muy especialmente por obra de autores como Gerber o Laband.

Los historiadores suelen explicar el fracaso de la Constitución de Weimar por el profundo desfase entre sus cláusulas, marcadamente democráticas y de importante contenido iusfundamental y social, y aquel pensamiento dominante entre los juristas y que abominaba a partes iguales del individualismo liberal y del reformismo socialista y que, sobre todo, no quería ver la soberanía residenciada en el pueblo, sino en el ejecutivo y no aceptaba pensar el Estado como instrumento de la sociedad, sino la sociedad al servicio de un Estado cuyos fines trascendían cualquier interés individual o grupal.

Ese predominio del pensamiento jurídico antidemocrático, anticonstitucional $y$ de gusto fuertemente autoritario explica en buena parte que en la doctrina de ese tiempo sobre la interpretación y aplicación del Derecho dominara, aun en medio de gran polémica, la llamada teoría subjetiva de la interpretación, a tenor de la cual las normas deben interpretarse y aplicarse ateniéndose a lo que con ellas quiso su autor, guiándose, por tanto, por la voluntad del legislador. Así, si el sentido de una cláusula legal no está claro, pues admite significados diversos, de entre éstos hay que elegir aquel que el autor de esa cláusula, el legislador, tenía en mente al dictarla, o el que mejor sirva a los propósitos con los que el legislador dio a la luz dicha cláusula. La consideración de la voluntas legislatoris, por tanto, como supremo principio rector de la praxis judicial.

No hace falta contar aquí por extenso qué ocurrió después de 1933 y de que Hitler y sus infames secuaces se hicieran con todo el poder. Estatismo organicista, voluntarismo y autoritarismo hallan entonces su síntesis plena, se aúnan en una fórmula común: el Fültrer, encarnación y supremo intérprete del sentir y la voluntad del pueblo alemán, es fuente máxima del Derecho, y toda norma jurídica debe interpretarse y aplicarse desde el absoluto respeto a la voluntad del Führer, que es tanto como decir la voluntad misma del Estado y del pueblo, que son la misma cosa.

Pero llegamos a 1945 y los nazis sufren su definitiva derrota. En esos momentos comienza una larga serie de sucesos sorprendentes y que forman parte destacada de la historia universal de la infamia. Aquellos profesores que di- 
jeron lo que dijeron y escribieron lo que escribieron entre 1933 y el momento en que se empezó a torcer el destino del III Reich, empezaron a proclamar al unísono que: a) ellos nunca habían estado de acuerdo con Hitler y el nazismo; b) que habían estado muy influidos pro el pensamiento de Kelsen, al que seguían con convicción; c) que el pensamiento jurídico de Kelsen se resume en la idea de que el Derecho es el Derecho y que toda ley que haya sido elaborada con respeto al procedimiento legislativo establecido es Derecho y debe ser obedecida por los ciudadanos y aplicada por los jueces, sin que quepa justificación de ningún tipo, ni jurídica ni moral para su desobediencia; d) que por eso ellos, obnubilados por Kelsen, no habían encontrado base teórica para resistirse a las aberraciones jurídicas del nazismo; e) que ellos siempre habían creído, y seguían creyendo, sin desmayo, en la democracia, el parlamentarismo, los derechos humanos y el Estado de Derecho.

Difícil será encontrar en toda la historia jurídica del siglo XX un mayor descaro ni una hipocresía más grande. Mintieron y falsearon a partes iguales. Mintieron sobre su pensamiento y su actuación al servicio de Hitler. Falsearon la historia, por ejemplo cuando dijeron que el pensamiento kelseniano era el dominante entre los profesores alemanes, ellos mismos, y desfiguraron radicalmente las tesis de Kelsen cuando repitieron que Kelsen no admitía excusa moral para la desobediencia al derecho válido y propugnaba el ciego acatamiento incluso de normas como las de los nazis. No ha de extrañarnos ese proceder cuando reparamos en que tales cosas las escribieron, después del 45, antiguos altos jueces y fiscales nazis con pasado un tanto sangriento, o profesores que medraron académicamente en su juventud a fuerza de adular a Hitler y sus esbirros y triunfaron después del 45 a base de alabanzas a los derechos humanos y a los valores de las Constituciones liberales, pero siempre, es curioso, denostando a Kelsen.

Porque eso fue lo que hicieron aquellos autores alemanes después de 1945: apresurarse a proclamar que el derecho positivo no agota el Derecho, y que del sistema jurídico forman parte principal ciertos valores morales que impiden su degradación en injusticia. Así nació la Jurisprudencia de Valores, de la mano de autores como Larenz y tantos otros cuyo pasado oscuro quedó olvidado durante décadas, las décadas en que los mismos sujetos siguieron controlando las universidades.

Ahora resumiremos sus tesis, pero antes unas palabras sobre el destino de la teoría subjetiva de la interpretación. Durante el nazismo se legisló mucho, y no todo ello fue derogado después de 1945, pues junto a aquellas abominables leyes racistas y homicidas, había otras, de tema moral y políticamente neutro 
y de depurada técnica, que se mantuvieron en vigor. Si tenemos presente que en aquel régimen que las produjo se entendía que era Hitler el supremo legislador y su voluntad la más alta fuente jurídica, ¿cómo mantenerse, después del 45, en la defensa de una teoría subjetiva que vendría a proponer que las normas se interpretasen con base en la voluntad de aquel genocida malnacido que las había mandado? Así que hubo que olvidarse por unas cuantas décadas de la teoría subjetiva de la interpretación y pasar a entender que el fin a considerar en la interpretación no puede ser el fin subjetivo del legislador, lo que éste hubiera querido o entendido, sino un fin objetivo, que se definía por alusión a los valores y propósitos que objetivamente la norma poseyera, o a los que tuviera sentido imputarle aquí y ahora, a tenor de las necesidades presentes y la convicciones vigentes. Éste será otro elemento que allanará el camino para el triunfo teórico y práctico de la Jurisprudencia de Valores, la cual tomará importante apoyo también en el paragrafo 20.3 de la Ley Fundamental de Bonn, que afirmaba (y afirma) que los poderes ejecutivo y judicial están sometidos "a la ley y al Derecho". Y se dijo: o en dicho precepto constitucional se contiene una redundancia, si es que la Ley agota lo que el Derecho sea o, si queremos salvar el sentido de ese artículo, habremos de admitir que hay Derecho más allá de la Ley, es decir, que hay Derecho más allá del derecho positivo, que éste, en resumen, no agota el Derecho. ¿Dónde está ese Derecho del más allá y en qué consiste? Está en el fondo innominado del ordenamiento y consiste en valores, valores que el juez puede descubrir y aplicar. Ésa fue la respesta de la Jurisprudencia de Valores, respuesta que tuvo inmediato eco en la Jurisprudencia del Tribunal Constitucional Alemán y la marcó durante décadas.

Para la Jurisprudencia de Valores las normas legales o de derecho positivo, es decir, los enunciados jurídico-positivos contenidos en la Constitución, las leyes, los reglamentos, etc., tienen su fundamento y perfecto complemento en todo un sistema articulado y consistente de valores que les subyace. Esos valores no son parte separada del Derecho, aditamento externo, sino elemento constitutivo y esencial del Derecho mismo. Gracias a esos valores los graves problemas que para su aplicación presenta el derecho positivo se tornan resolubles cuando se trata de aplicar a los casos el conjunto total del Derecho, incluyendo tales valores. Así, las lagunas no habrán de resolverse desde la discrecionalidad del juez que no encuentra norma positiva, pues podrá hallarla prepositiva, yacente en ese sustrato valorativo; las antinomias se darán sólo en la superficie, al nivel de los enunciados, pues en su fondo valorativo el Derecho brinda solución coherente y única para cada caso, ya que la justicia, en tanto que supervalor, no puede ser contradictoria o equívoca; y, sobre todo, lo que en el plano del lenguaje de las normas positivas puede dar lugar a 
dudas interpretativas, se vuelve claro cuando se atiende a ese fondo material de valores que alienta bajo cada norma e inspira su lectura desde los casos, por lo que interpretar ya tampoco es elegir, más o menos razonadamente, entre significados posibles de la norma, sino conocer, descubrir, allá en el fondo del Derecho, en su subsuelo de valores, en su cimiento axiológico, la verdadera solución de cada caso.

Más allá de estas notas comunes a toda esta corriente de la Jurisprudencia de Valores, sus diversos cultivadores diferían al tiempo de describir y fundamentar la ontología, de corte metafísico, en que se asentaba. Unos se inspiraban en teorías materiales de los valores, del estilo de la de Scheler; otros pergeñaban teorías de la "naturaleza de las cosas", con las que pretendían mostrar que los órdenes sociales posibles están predeterminados en un orden natural del ser (en el fondo, un orden de la Creación, de nuevo) que tiene el valor y la fuerza racional de los cuerpos y las relaciones geométricas; igual que hay un orden y una interrelación necesaria de los cuerpos geométricos, hay un tal orden de la sociedad (de la misma manera que por definición un círculo no puede ser cuadrado, ni aun cuando un loco legislador así lo ordenara, tampoco un matrimonio, por ejemplo, podría ser disoluble -eso se decía primero- o entre personas del mismo sexo -eso se dice ahora-). Otros pretendían describir ese vínculo entre el ser necesario de las cosas y la génesis de reglas jurídicas mediante la referencia a estructuras lógico-reales. Y así sucesivamente.

Más allá de esas discrepancias, podemos ver en la Jurisprudencia de Valores el primer momento importante de ruptura del pensamiento jurídico conservador y antipositivista con los esquemas clásicos del iusnaturalismo. Desde entonces ya no es acertado decir que el rival principal del positivismo jurídico está en el iusnaturalismo, que es doctrina bastante marginal desde mediados del siglo XX al menos, básicamente reducida a ideología legitimadora de dictaduras tercermundistas, pero ya no demasiado presente (con contadas excepciones, de la cual una importante sería por ejemplo Finnis) en el debate actual sobre cómo debe proceder el juez al decidir y a qué debe atenerse al interpretar las normas y los hechos del caso.

¿Por qué tildo esta doctrina de conservadora? Desde luego, no me influye el pasado político de muchos de los que la abrazaron después del 45 , pues no hay manera de probar que su caída del caballo de camino a Karlsruhe (sede del Tribunal Constitucional Alemán) no fuera genuina y punto de arranque de un sincero cambio de convicciones: vieron la luz de la democracia y abominaron de las tinieblas del estatismo, el organicismo y el odio a los derechos fundamentales individuales. Pero, aun así, lo que esta doctrina ofrece es un 
claro límite al legislador democrático y un patente otorgamiento de la primacía a los jueces, que ya no son meros guardianes de la Constitución, sino custodios del Orden Objetivo, de la Justicia, del Bien. El imperio de la ley que es propio del Estado de Derecho y que no tiene más límite que el de la compatibilidad con el texto constitucional, se ve sometido a una cortapisa que no estaba en el diseño inicial de tal Estado ni de la democracia: para que una ley sea Derecho y vincule al juez no sólo ha de ser formalmente conforme con la Constitución, sino también materialmente compatible con el Orden Necesario del Ser, o con el Sistema Objetivo de Valores, o con la Naturaleza de las Cosas, o con lo que quiera que sea el nombre de esa realidad que ya no permite al legislador mandar lo que quiera que la Constitución no prohíba, sino que le impele ha acertar con lo que objetivamente sean el Bien y la Verdad. Tras la que parecía la crisis irreversible del iusnaturalismo, esta nueva doctrina vuelve a entronizar el sacerdocio de los jueces, guardianes de las esencias de lo jurídico y vigilantes de un legislador caído en el descrédito y abominado por todos. Comienza así su itinerario la ideología jurídica predominante en nuestros días y que es el contrapunto exacto de aquel mito del legislador racional que regía en los inicios del Derecho moderno y de la codificación. Hoy el mito imperante, objeto de fe unánime y de exigente veneración, es el mito del juez racional. Los valores están en buenas manos, pues frente a la estulticia constitutiva del legislador, el juez es sabio por definición; frente a la venalidad de los tribunos del pueblo, el generoso y desinteresado servicio de los jueces a la Justicia; frente a la corruptelas de los partidos y los Parlamentos, la integridad sin mácula de las judicaturas.

Ese camino iniciado por la Jurisprudencia de Valores tendrá las etapas principales de su ulterior desarrollo en Dworkin y en algunos de los llamados neoconstitucionalistas. No quiero, para nada, decir que Dworkin construya su doctrina apoyándose en semejante antecedente, pues todo hace pensar que nada sabía de él. Pero, sea como sea, la aportación de Dworkin va a consistir en acercar a la sociedad esos valores extrapositivos, pero jurídicos, para los que la Jurisprudencia de Valores aún buscaba un anclaje en exceso metafísico y ahistórico. El paso siguiente, consumado por el neoconstitucionalismo, consistirá en colocar esos valores, ya sociales, dentro de la Constitución y, al mismo tiempo, retomar el componente metafísico, con lo que la dialéctica hegeliana parece haberse confirmado en una nueva y sorprendente síntesis: la Constitución positiva es Constitución metafísica. Ya no será el Derecho el que se desdoble en una parte superficial o positiva (imperfecta) y una parte profunda o prepositiva (perfecta), sino que es la parte suprema del derecho positivo, la Constitución, la que se duplica en Constitución formal o procedimental -imperfecta- y Constitución material -perfecta-. La primera la puede 
conocer y entender cualquiera, tanto en lo que tiene de preciso como en lo que deja indeterminado; la segunda la calan y observan con todo rigor y precisión los profesores y los tribunales, en particular los Tribunales Constitucionales, capaces los unos y los otros de ver en ella y de extraerle lo que sólo ellos pueden descubrir allí, cosas tales como cuántas cárceles debe haber en un país o cuál puede ser exactamente la tasa máxima de interés de los créditos hipotecarios. Apoteosis del mito del juez racional. Pero vamos por partes y fijémonos primero en Dworkin.

La obra primera que da fama mundial a Dworkin, su Taking Rights Seriously (Los $D$ erechos en serio), se plantea expresamente como oposición a la doctrina de la discrecionalidad judicial sostenida por Hart y a la que luego aludiremos. El argumento es ingenioso. Hart había dicho que las normas se expresan en el lenguaje ordinario, que éste adolece siempre de vaguedad y que, por tanto, hay casos jurídicos claros y casos dudosos. Los primeros son los que caen en el núcleo de significado de los enunciados normativos o completamente fuera de toda referencia de los mismos. Así, si una norma prohíbe pasear por el parque en vehículo resultará obvio que un es un vehículo, e igual de obvio resultará que un cigarrillo no lo es, pero cabrá dudar si la prohibición abarca las bicicletas, los triciclos o el vehículo eléctrico en el que se desplace un minusválido. Respecto de estos casos dudosos la solución no estaría predeterminada en las normas positivas (en ésa que prohíbe andar por los parques en "vehículos"), sino que dependerá de la interpretación que de las normas haga en cada caso el juez (lo que éste defina a tal efecto como "vehículo"), y tal opción entre interpretaciones posibles es esencialmente discrecional y no puede ser de otro modo, según Hart. Y por ahí ataca Dworkin.

Según Dworkin, reconocer dicha discrecionalidad judicial equivale a admitir que la norma que decide esos casos dudosos es una norma que: a) es creada por el propio juez, aunque sea dentro del espacio o margen de posibilidades que la vaguedad de la ley le deja, y b) es aplicada retroactivamente, pues se usa para decidir sobre hechos acontecidos por anterioridad a dicha creación judicial de la norma, como son los hechos del caso con ella juzgados. El problema es de entidad y apunta un flanco importante de la teoría positivista del Derecho y de su aplicación, pero ¿tiene solución? Según Dworkin, sí. La solución consiste en asumir que el Derecho se compone de algo más que de esos enunciados normativos que solemos llamar derecho positivo, enunciados del tipo del que prohíbe los vehículos en los parques y que resultan tan incompletos como pauta decisoria de ciertos casos. ¿Qué es ese algo más? Principios. El sistema jurídico se compone de reglas, que son esos enunciados que tienen la estructura "si... entonces", supuesto de hecho y consecuencia jurídica, y prin- 
cipios, que son normas que nos dicen que unas cosas están bien y otras cosas están mal, pero sin especificar cuáles son las unas y las otras, lo que no impide que el juez pueda acabar conociendo perfectamente y en cada caso eso que los principios mandan sin decir.

¿Y dónde viven los principios? No, o no necesariamente, en la obra del legislador, sino ante todo y primariamente en la moral social. Según Dworkin, todo derecho positivo, todo conjunto de normas jurídico-positivas se asienta en y encaja con una determinada moral social, la moral propia de la sociedad histórica en la que el legislador (o los jueces) alumbra las normas positivas. Sin abarcar y comprender dicha moral social de fondo no podremos saber a qué vienen ni cuál es la razón de ser de esas normas positivadas, de esos concretos mandatos del legislador. $Y$, en cuanto son condición de comprensión y, con ello, de aplicación mínimamente coherente de dichas normas positivas, las normas morales que las inspiran y les sirven de explicación son parte del Derecho mismo, su parte esencial, su parte más profunda. Cada norma positiva, pues, cada regla dada por el legislador positivo, tiene su explicación en los patrones morales de la respectiva sociedad, y puesto que ésa es su esencia no puede contradecirla a la hora de hallar aplicación. Quiere decirse que si la aplicación de una de esas reglas choca con los propósitos de las normas morales que están en su base, deben éstas prevalecer en detrimento de la pura dicción de aquélla, de su semántica, sin que por ello se contraríe el Derecho, pues éste es la suma de dos partes: el derecho positivo, que es la parte superficial o menos importante, y la moral social desde la que ese derecho positivo se explica, que es la parte profunda y fundamental. Es decir, un caso que semánticamente es fácil, pues encaja sin duda en el núcleo de significado de la norma, se torna caso difícil cuando la solución que la norma contiene para él nos resulta escasamente conciliable con la moral social dominante, y en ese caso ésta debe prevalecer, pues no sólo es moral, es también Derecho, la parte más alta y valiosa del Derecho.

Algún autor le preguntó en cierta ocasión a Dworkin si en un derecho racista, que sea reflejo de una moral social fuertemente racista, el juez debe considerar que esa base moral racista es parte del sistema jurídico mismo de tal país, de modo que las normas positivas racistas deban interpretarse e integrarse desde ese racismo social que las inspira. No respond ió cosa muy coherente Dworkin a eso. Insinuó que en ese caso la moral que guiara al juez no debería ser esa moral positiva, socialmente vigente e inspiradora de las normas de derecho positivo, sino una moral crítica o de los derechos humanos. Con ello no hizo más que mostrar que cuando pintan bastos siem pre acaban estas teorías reculando hacia el iusnaturalismo de toda la vida. 
Ya tenemos esbozada la ontología jurídica de Dworkin, a tenor de la cual el Derecho es un compuesto de normas jurídico-positivas y, en un estrato más importante, aquellas normas de la moral social que se integran coherentemente con las anteriores y sirven para su explicación de fondo, valen para dar cuenta de su porqué en una teoría de conjunto y consistente. Ahora nos resta examinar el problema epistemológico. ¿Pueden conocerse con precisión esas normas morales que son al tiempo jurídicas aunque no sean derecho positivo? ¿Podemos hallar en ellas respuesta exacta y precisa para absolutamente cualquier caso cuya solución de derecho positivo nos resulte dudosa o nos parezca inconveniente? La respuesta de Dworkin es que sí. Para este autor el sistema jurídico, con esa doble composición que ya sabemos, contiene en su seno una y sólo una respuesta correcta para cada caso que se le somete. Por tanto, no hay sitio para discrecionalidad ninguna y la labor del juez no es propiamente decisoria sino, en puridad, cognoscitiva: el juez aplica Derecho, sí, pero no optando entre las soluciones que le parezcan compatibles con la ley o coherentes con ella, sino averiguando, descubriendo, conociendo, cuál es exactamente y en puridad la solución única que el sistema jurídico reserva para cada caso. Si hay casos difíciles no es porque su solución no esté perfectamente predeteminada en el sistema jurídico, sino porque es difícil hallarla o complicado fundamentarla. Pero estar, está.

¿Y quién puede conocer esa solución única e indubitada que en el fondo del Derecho yace para cada caso, esperando ser descubierta? Pues podría conocerlas todas y con total seguridad un juez perfecto. Hasta nombre le pone Dworkin a ese juez ideal: se llama Hércules. El juez Hércules es aquel juez absolutamente sabio y experto, que sabe todo de todo, al menos todo lo necesario para dar con esas soluciones que el común de los mortales difícilmente pueden conocer con seguridad. Como ninguno somos verdaderamente Hércules, más bien vulgares mortales, tampoco podemos saber exactamente qué es eso que idealmente deberíamos saber para estar en condiciones de saber lo que hay que saber. Pero si fuéramos Hércules lo sabríamos y, con ello, daríamos (al menos si fuéramos jueces) con la única respuesta correcta para cada caso. Ciertamente el juez Hércules es un juez ideal, omnisciente, y que precisamente por ser omnisciente, sabedor de todo, sabe también cuál es la correcta solución judicial de cada caso. En cambio, un juez de carne y hueso será tanto mejor juez y, consiguientemente, tanto más vedaderas sus decisiones, cuanto más su saber se aproxime al saber ideal de Hércules; es decir, cuanto más sepa de eso que hay que saber pero que no se sabe lo que es.

Dworkin ha sido muy útil para los que han querido rematerializar la Constitución y ponerla al servicio de sus valores (¿de ellos?) pero que no deseaban 
comulgar con las rancias filosofías, tipo Scheler, que inspiraban a los de la Jurisprudencia de Valores. El esquema resultante quedaría más o menos así: a) si por debajo de todo derecho positivo está la moral social que lo inspira, lo explica, lo condiciona y lo complementa, por debajo de la suprema norma positiva, la Constitución, estarán las más altas normas de esa moral social de base. b) Si el Derecho se perfecciona, de modo que en lugar de vaguedades, antinomias y lagunas, habilitadoras todas ellas de la discrecionalidad judicial, contiene una única solución correcta para cada caso, habrá que pensar que si integramos la Constitución-enunciado, o Constitución lingüística, con esos componentes objetivos de la moral social, la Constitución puede ser leída como prefiguración y síntesis de todas las soluciones únicas que en el sistema jurídico se contienen para todos los casos. c) Si esa solución única correcta para cualquier caso se contiene en el sistema jurídico, e in nuce ya en la Constitución, y si puede ser conocida perfectamente por un juez Hércules perfecto, cuanto más sabios y expertos sean los jueces, tanto más se aproximarán a ese modelo de Hércules y tanto más podremos confiar en que sus decisiones son las objetivamente correctas y no mero ejercicio de discrecionalidad. d) Los jueces más sabios y expertos son los de los tribunales más altos, y los más de los más los de las Tribunales Constitucionales, por lo que podemos y debemos pensar que sus decisiones son las objetivamente correctas para cada caso o, al menos, las más correctas que un ser humano puede alcanzar y aplicar. e) Puesto que Dworkin y compañía nada han dicho de la posibilidad de un legislador Hércules, podemos seguir tranquilamente suponiendo que el legislador es bruto sin remisión, por mucho que represente al pueblo, o tal vez por eso, y sólo nos consolará de sus yerros la confianza en que los primos de Hércules que integran las más altas Cortes dejarán sin aplicación toda mandato del legislativo que se oponga el Bien y a la Verdad. f) Porque, al fin y al cabo, la verdadera Constitución es el Bien y la Verdad, de los que la Constitución lingüística no es sino incompletísima pista. Esa Constitución lingüística, que habla a los ciudadanos en su lenguaje, con las palabras del lenguaje ordinario, no es la verdadera Constitución, sólo su epifenómeno, una versión simplificada para ciudadanos carentes de los atributos del sabio platónico. La verdadera y auténtica Constitución sólo le habla, sin palabras, a Hércules. $Y$ un poquito también a sus testaferros.

La última vuelta de tuerca, hasta hoy, la dan los más radicales representantes del denominado neoconstitucionalismo. Hasta aquí el problema estaba en que la Constitución era sometida a una especie de desdoblamiento: por una parte, lo que en ella está expreso, por otra, lo que en ella se contiene sin expresarse. El gran mérito de los neoconstitucionalistas es haber descubierto la manera de hacer expreso lo inexpresado: en las cláusulas valorativas y las proclamas de principio que en la Constitución se contienen se tornaría derecho constitucional 
positivo ese entramado de valores morales que son la parte superior y principal del Derecho, ahora ya por fin revestidos de Derecho constitucional positivo. La Constitución se despositiva al positivarse en ella los valores de fondo. $\mathrm{O}$, dicho mejor, al positivarse en la Constitución los valores, la positividad de la Constitución deja de importar y pasan a contar como Constitución ya sólo esos valores supuestamente positivados. Habrá que explicar esto un poco.

Antes el problema era el de cómo traer al Derecho valores como la Justicia sin que pareciera que la naturaleza del Derecho era doble, una parte positiva y la otra no positiva. Ese fue siempre el problema del iusnaturalismo y el arranque de sus mayores críticas. Pero desde que Constituciones de las últimas hornadas contienen, en lugar muy destacado, cláusulas abundantes en que proclaman su inspiración en valores como la Justica, la Solidaridad, la Dignidad, etc. o principios-guía como el del libre desarrollo de la personalidad, aquel problema ya no es tal. $Y$ no lo es porque mediante tal mención en el texto constitucional dichos valores habrían quedado positivados como norma de Derecho y, además, en su nivel más alto, a escala constitucional. La Justicia, por ejemplo, ya no es un importante valor externo al Derecho, sino parte plena del sistema jurídico, pues al mismo lo incorpora su suprema norma, la Constitución. Quiere esto decir que una norma legal que, aplicada al caso que el juez resuelve, diera como resultado una solución injusta de dicho caso, debe ser dejada de lado por tal juez y en su lugar debe resolver con lo que para ese asunto la Justicia mande. ¿Y qué mandará? Pues lo que el juez vea que manda, líbrenos Dios de decir que es la Justicia mera tapadera de la discrecionalidad judicial. La Justicia es lo que es y bien claro dispone lo que toca para cada caso y situación. Y lo que ella no diga lo dirán la Dignidad, la Solidaridad o el Libre Desarrollo de la Personalidad. Sin duda. Sin discusión.

Lo anterior supone, según esta doctrina neoconstitucionalista, que cuando el contenido de una ley sea considerado injusto por el órgano judicial competente en materia de incostitucionalidad, dicho órgano deberá declarar la inconstitucinalidad de dicha ley por oponerse al valor constitucional Justicia. Eso por un lado. Por otro, cuando la ley no declarada inconstitucional, o, incluso, previamente declarada constitucional, proporcione para el caso una solución que no le haga justicia al mismo, habrá que hacer dejación de tal ley y resolver dicho caso desde lo que para él disponga la Justicia; o cualquier otra valor constitucional que venga al caso.

Naturalmente, siempre queda pendiente la cuestión epistemológica: puesto que en una sociedad plural y de libertades con toda legitimidad rigen socialmente múltiples y muy variadas concepciones sobre qué sea lo justo, a qué 
obliga la solidaridad o en qué consiste el desarrollo libre de una auténtica personalidad, ¿cómo puede conocer ese juez el verdadero contenido de tales valores o principios, a fin de que podamos confiar en que no haga pasar por tales lo que no son más que sus personales convicciones sobre el particular? Y la única respuesta que esta doctrina insinúa creo honestamente que puede sintetizarse así: a) Si la Constitución expresamente menciona tales valores, habrá que pensar que es porque existen; b) puesto que existen, habrá que pensar que existen con pleno y preciso contenido; c) puesto que existen con pleno y preciso contenido, habrá que pensar que dicho contenido se puede conocer; d) puesto que ese contenido se puede conocer, habrá que pensar que su supremo conocimiento está al alcance de los órganos a los que la Constitución misma confía su tutela; e) puesto que la Constitución confía tal tutela a los jueces y tribunales y al Tribunal Constitucional, habrá que pensar que éstos pueden conocer supremamente el contenido de aquellos valores constitucionales y lo que los mismos disponen para cada caso; e) por tanto, el verdadero e indubitado contenido de lo que los valores constitucionales prescriben para la solución de cada caso es lo que al respecto digan los jueces y tribunales, y especialmente el Tribunal Constitucional.

Sinteticemos este apartado y el anterior. Hemos pasado revista a dos grupos de doctrinas que niegan y combaten la discrecionalidad judicial. Aparentemente son dos doctrinas muy opuestas, pero sus profundas coincidencias son sorprendentes en grado sumo. Las unas y las otras beben en un mito, aquellas del XIX en el mito del legislador racional o de la racionalidad inmanente a un Derecho ideal; éstas de la segunda mitad el $X X$ y comienzos del $X X I$ se apoyan en la creciente fuerza del mito del juez racional. $Y$ ambas son formalistas, pues participan por igual de las siguientes ideas interrelacionadas: a) el sistema jurídico es perfecto, pues en algún lugar de su fondo contiene predeterminada la solución correcta para cualquier caso; b) esa solución correcta puede y debe ser conocida y aplicada por el juez; c) existe algún método que, rectamente aplicado, permite al juez aplicar a cada caso que resuelve esa única solución correcta; d) no queda sitio para la discrecionalidad judicial, que es mala cosa; e) el juez es mero aplicador del Derecho, nunca su creador; f) la ideología de los jueces no condiciona ni mediatiza sus decisiones, al menos cuando el juez se esfuerza bastante por conocer aquellas soluciones prefijadas para todo caso en el sistema jurídico, o cuando es un juez de suficiente nivel.

\section{DOCTRINAS QUE AFIRMAN LA DISCRECIONALIDAD JUDICIAL}

Entre las corrientes del pensamiento jurídico que han mantenido que la discrecionalidad judicial existe y es inevitable, podemos diferenciar una radical y 
una moderada. La primera, representada por numerosos autores del realismo jurídico y, más recientemente, por algunos de los adscritos al movimiento Critical Legal Studies, afirma que dicha discrecionalidad es total y absoluta, que todo lo que hace el juez lo hace siempre y por definición a su libre albur y que la cosa no tiene posibilidad de limitación ni arreglo. La segunda corriente, moderada, tiene su mejor ejemplo en el positivismo jurídico del siglo $X X$, paradigmáticamente representado por Hart, y mantiene que el ejercicio de discrecionalidad es constitutivo de la labor judicial, pero que dicha discrecionalidad puede y debe ser limitada, y lo es de hecho. Repasemos resumidamente estas dos posturas.

\section{1. ¿Son realistas los realistas que afirman que todo juez hace meramente lo que le da la gana?}

En verdad no fueron sólo los autores pertenecientes al realismo jurídico, ya sea el escandinavo o el norteamericano, los que insistieron en que el juez disfrutaba de una libertad total para decidir a su antojo, al tiempo que, con lo mismo, la sutil demarcación entre discrecionalidad y arbitrariedad desaparecería, pues, a fin de cuentas, toda decisión, por libérrima, sería como arbitraria, y lo de discrecional no sería sino un caritativo eufemismo. Tres razones principales habría de que el libre hacer del juez no conozca auténtico límite ni traba alguna, por mucho que se finjan seguridades jurídicas o atadura a las normas, y en cada una de esas razones insistió particularmente una escuela distinta: la Escuela de Derecho Libre en las insuficiencias del sistema jurídico; el realismo en la soberanía de facto de los jueces; y, contemporáneamente, los del CLS en la radical indeterminación del lenguaje jurídico.

En las dos décadas primeras del siglo $X X$ aparecieron en Alemania una serie de autores (Kantorowicz, Fuchs, etc.) que se adscribían a un movimiento de contornos un tanto vagos y que recibió el nombre de Escuela de Derecho Libre. Fueron los más furibundos e insistentes negadores de aquellos tres dogmas del formalismo ingenuo del XIX, plenitud, coherencia y claridad del sistema jurídico. En tales proclamaciones de la doctrina anterior no veían más que un descarado engaño, que tenía por finalidad alejar del juez la responsabilidad por sus decisiones, imputando éstas por completo a aquellos mágicos atributos de la legalidad o los conceptos. La doctrina jurídica sería generadora de ideología, en cuanto falsa conciencia, pues desde las Facultades de Derecho mismas se cebaba el engaño de que el juez nada pone de su parte, por lo que, así disfrazados de irrepochables autómatas, ya podían los jueces fallar como les daba la gana o como convenía a sus patronos, sin que nadie osara proclamar la obvia verdad, tan celosamente negada, de que el rey está desnudo, es 
decir, que la sentencia la pone el juez, no el sistema jurídico mismo con sólo sus normas y con el juez como puro y simple portavoz. No pretendían negar la importancia de la ley ni su grave significado político, sino desmitificarla y enseñar que alcanza para poco y que, sus oscuridades, consecuencia de que el lenguaje del legislador, que es el nuestro, tiene poco de exacto; sus incoherencias, consecuencia de que a menudo el legislador pierde cuenta de sus propia obra debido a su volumen desmesurado; y sus insuficiencias, seguidas de que el mundo cambia más aprisa de lo que culquier legislador puede prever y responder, convierten al juez, malgré lui, en centro del sistema y señor cuasiabsoluto del Derecho. Uno de sus dichos favoritos era que por mucho que el legislador produzca siempre serán más las lagunas que los casos que encuentren en sus normas solución.

La consecuencia principal que extrajeron parecía bien obvia, aunque se les hizo muy poco caso en la posteridad: hay que modificar la formación y el modo de selección de los jueces. Si el juez no es más que un robot, un puro autómata, un simple hacedor de silogismos elementales, vale como juez cualquiera que esté en sus cabales. Pero si resulta que el juez verdaderamente decide y determina y, con ello, es señor de nuestras vidas y de importantes parcelas del destino social, necesitamos jueces con capacidad para entender lo que resuelven y sensibilidad para hallar las soluciones menos malas. Y para todo ello deberán saber más que pretéritas historias de Ticio y Cayo y conocer de más cosas que de metafísicas conceptuales: habrá que enseñarles ética, teoría política, economía, psicología, etc.

Todas las versiones del realismo jurídico, tanto la norteamericana como la escandinava, coinciden en el postulado básico de que no hay más cera que la que arde ni más Derecho que lo que dicen las sentencias. Frente al Derecho en los libros, ese Derecho de raíz formal y escasísima eficacia que figura en los códigos y repertorios legislativos, el Derecho de verdad es el que sirve para responder la pregunta que se hace el "hombre malo": "¿qué me puede ocurrir si hago tal cosa?" Para contestar qué le puede ocurrir a uno que haga algo, lo que importa es saber cómo vienen fallando los tribunales cuando juzgan tal tipo de acciones. Y el modo en que los tribunales respondan a estos o aquellos comportamientos dependerá de factores sociológicos y psicológicos, pero nada, o casi, del dato formal de cuáles sean las palabras de la ley vigente. Así que comprender el Derecho será conocer a los jueces de carne y hueso y averiguar qué factores, aquí y ahora, los determinan: ideologías, intereses, extracción social, sentimiento corporativo, ambiciones, etc. Porque, conforme a un lema central de los realistas, los jueces primero deciden y después motivan. Es decir, antes escogen el fallo del caso, guiados por sus personales 
móviles, y luego redactan una motivación con la que disfrazan de resultado de la razón jurídica lo que no es más que producto de su personal cosecha, de sus pasiones subjetivas.

Algunos de los más radicales autores norteamericanos que en las últimas décadas del siglo XX se adscribieron al movimiento llamado Critical Legal Studies actualizaron los postulados de esas dos pasadas corrientes. Su tesis más insistente hace hincapié en la radical indeterminación del lenguaje jurídico. El lenguaje de las normas carece de toda virtualidad significativa y, por ende, de cualquier capacidad para dirigir el comportamiento decisorio del juez. La ley es puro flatus wocis, significante sin significado, ruido sin referente ni mensaje tangible de ningún tipo, simple apariencia carente de toda capacidad directiva, y por esa razón el juez no está en realidad sometido a nada que no sea la presión de los poderes establecidos y las ideologías dominantes. La seguridad jurídica es, en consecuencia, supremo engaño que hace a los ciudadanos sentirse protegido por las normas, allí donde, en realidad, no están sino a merced de los poderes, de los que el juez es servidor inerte, como una marioneta.

Pese a tan profundo escepticismo, cuentan las crónicas que cuando un profesor de los pertenecientes al CLS sufre alguna afrenta o padece algún perjuicio que le resulta intolerable, acude a los tribunales, interpone la correspondiente demanda y solicita humildemente justicia. Será su meritoria forma de pasar por un ciudadano más, se supone.

\section{2. $\mathrm{Ni}$ apocalípticos ni integrados: el positivismo jurídico del siglo XX.}

Si hay una idea clarísimamente presente en todos los autores relevantes del positivismo jurídico del siglo XX (Kelsen, Hart, Bobbio...), es la de que la aplicación del Derecho por vía de decisión judicial no es ni puede ser, en modo alguno, un puro silogismo, una mera subsunción.

Buena parte del positivismo del XX ha sido formalista en materia de teoría de la validez del $D$ erecho, pues a afirmado, con Kelsen a la cabeza, que una norma es jurídica cuando ha sido creada con arreglo a las pautas formales y procedimentales sentadas por el propio ordenamiento jurídico-positivo, y que esa condición de validez o juridicidad que posee la norma así creada no se pierde por causa de su injusticia o su incompatibilidad con esta o aquella ideología, religión, cosmovisión o inclinación. Ésta es la tesis positivista de la separación conceptual entre Derecho y moral, tesis que, como antes se indicó, nada tiene que ver con la reducción de la obligación moral a obligación jurídica, radical y expresamente rechazada por los tres autores que he mencionado, ni con 
la más mínima afirmación de la superioridad de la obligación jurídica sobre la obligación moral. Y tampoco se relaciona con ningún género de doctrina abruptamente formalista de la decisión judicial. Para probar esto último, debería bastar con leer el capítulo último de la kelseniana Teoría pura del D erecho, en cualquiera de sus versiones, cuya claridad y rotundidad es meridiana, hasta el punto de que en materia de decisión judicial Kelsen está muchísimo más cerca del realismo jurídico que de aquella metafísica idealista de la Jurisprudencia de Conceptos, que él criticó sin compasión, metafísica idealista que, como ya dijimos, hoy vuelven a cultivar dworkinianos y zagrebelskys de toda laya.

Si hay un autor positivista que resulta claro para nuestro tema de la discrecionalidad, ése es Hart. En su obra EI concepto de D erecho explica que el lenguaje de las normas, que es parte del lenguaje ordinario, tiene márgenes de vaguedad, lo que Hart llama zonas de penumbra. Por tanto, algunos casos, los que caen dentro de esa zona de indefinición lingüística de las normas, no reciben de éstas una solución clara y terminante, sino que en principio son varias y distintas las soluciones que la norma permite para ellos, y tendrá que ser el juez quien, por vía de interpretación, precise ese significado que en el enunciado previo de la norma permanece impreciso. Y esa labor de precisión, de interpretación, de concreción de la norma para que al aplicarla al caso ya dé sólo una solución y no la posibilidad de varias, tiene un componente esencialmente discrecional.

Así pues, Hart discurre por un camino intermedio entre dos extremos. Por un lado, discrepa de aquel positivismo ingenuo del XIX, que pensaba que los enunciados normativos eran perfectamente claros y unívocos, con lo que ni haría falta interpretarlos antes de su aplicación a los casos ni dejaban ningún resquicio para la libertad decisoria del juez. Por otro, discute también el escepticismo radical de los realistas, pues la práctica jurídica no es ese caos de imprevisibilidad en que consistiría si fuera verdad que los enunciados jurídicos en nada determinan al juez y que éste hace siempre y en todo caso lo que le da la gana, sin el más mínimo límite. Solemos acertar y suelen coincidir los jueces en la solución de los casos fáciles, los que caen en el núcleo significativo del enunciado jurídico aplicable, y difícilmente podemos prever la solución segura de los casos difíciles, los que se mueven en la zona de penumbra de tales enunciados, respecto de los cuales la propia jurisprudencia discrepa, pues cada juez puede hacer distintos usos de esa constitutiva discrecionalidad a que en términos prácticos se traduce la indeterminación de la norma en dicha zona. Por tanto, entre quienes dicen que no existe discrecionalidad, ya sean los de la Escuela de la Exégesis, los de la Jurisprudencia de Conceptos o los de Dworkin, y los que dicen que sí existe y 
es absoluta y total en todos los casos, Hart sostiene que ni lo uno ni lo otro: sólo cierta discrecionalidad es inevitable, pero en lo que es inevitable es inevitable. $Y$ en ese margen, lo único que podemos hacer es exigirle al juez que justifique exigentemente, mediante razones lo más convincentes y compartibles que sea posible, sus opciones y las valoraciones en que se basan, pero tales razones con que el juez motiva su decisión en los casos difíciles no serán nunca razones puramente demostrativas, jamás podrán ser prueba plena de que dio con la única respuesta correcta, sencillamente porque un caso no tiene una única respuesta correcta cuando las palabras de la ley permiten varias. Más allá del lenguaje en que las normas jurídicas se expresan, no hay verdad jurídica ninguna: ni en conceptos ideales ni en sistemas lógicos ni en valores ni en la moral social ni en el derecho natural ni en el oráculo de Oxford. Por eso el Derecho tiene siempre, también en su práctica aplicativa y decisoria, un componente político, de poder, y no es ciencia exacta ni mero ejercicio de conocimiento de verdades inmanentes o trascendentes. El juez no tiene ni metro con que medir exactamente la solución única que a cada caso conviene, ni balanza en que pesar las alternativas decisorias que se enfrentan, y por eso la decisión en Derecho, al menos en esos casos que llamamos difíciles, no es mera cuestión de medida... ni de ponderación. Medida o ponderación son palabras que valen como metáforas, no como descripción rigurosa de lo que el juez hace al fallar. Para explicar esa su labor es más exacto y honesto usar el término de siempre: valoración, juicio valorativo. Las soluciones que la ley no prefigura claramente no están prefiguradas en ninguna parte, ni en el cielo de los conceptos ni en el subsuelo de los valores o los principios, las construye el juez bajo su responsabilidad. Y la mayor parte de los casos que llegan a los jueces les llegan precisamente por eso, porque la ley no da de antemano solución inequívoca y cada parte se acoge a una de las soluciones que el tenor de la ley permite.

¿A alguien le sorprenderá aún esta afirmación de que según opinión común del positivismo jurídico del siglo XX la decisión judicial es esencialmente juicio valorativo, opción reflexiva y argumentada entre alternativas, en lugar de medición exacta, simple cálculo o puro pesaje? Medición exacta, simple cálculo o puro pesaje es lo que para la decisión judicial afirmaban hace siglo y medio los de la Escuela de la Exégesis o la Jurisprudencia de Conceptos, repito, y lo que siguen manteniendo hoy muchos seguidores de Dworkin o el último Alexy, especialmente los que trabajan en los altos tribunales y desde allí ejercen un poder decisorio que quieren disfrazar de rigor científico, o una acción política que quisieran hacer pasar por objetivo ejercicio de la razón práctica.

¿Qué consecuencias tiene para el estatuto del juez el reconocimiento positivista de su importante discrecionalidad? Pues significa que la decisión del 
juez tiene un elevado componente de responsabilidad personal, que no puede traducirse en responsabilidad jurídica. Al juez sólo se le pueden pedir cuentas de su decisión en cuanto quede demostrada su mala fe o patente por completo su desvarío. Quiere decirse que si es el propio sistema jurídico el que al juez le deja la posibilidad de optar entre soluciones alternativas, compatibles con el tenor de las normas, no podemos luego castigarle por ejercer esa facultad que es constitutiva de su función. Es decir, si en Derecho para los casos difíciles, para los casos que caen en la zona de penumbra, no hay solución correcta, no podemos en dichos casos castigar al juez por no aplicar la solución correcta. Para la ley solución correcta es cualquiera que no vulnere su texto. Para cada uno de nosotros, ya seamos ciudadanos de a pie, fiscales o jueces de instancias más altas, solución correcta será la que más nos guste o nos convenga. Pero castigar por prevaricador al juez que no imponga el fallo que nosotros prefiramos es tanto como decir que no hay en Derecho más solución que la que a nosotros nos agrade, seamos "nosotros" quienes seamos: ciudadanos simples, ministros, Tribunal Supremo o Tribunal Constitucional. Y eso no es así. Y menos aún en un Estado de Derecho, en el que altas dosis de discrecionalidad judicial e independencia de los jueces son dos caras de la misma moneda, un doble precio a pagar por nuestras libertades. Porque donde ni se admite la discrecionalidad ni se respeta la independencia acaba siempre existiendo una tiranía, aunque sea la tiranía de los jueces que más mandan. Que dichas tiranías pretendan siempre legitimarse mediante la invocación de los más evanescentes valores de los que la Constitución mencione, no es sino una más de las argucias de que suelen valerse los abogados con menos escrúpulos y los políticos con mayor descaro, unidos siempre por el interés de mandar sin pasar por las elecciones o de legitimarse simbólicamente con sus sentencias para promocionarse en el camino hacia las urnas. Pura impostura, en todo caso. 